Article

\title{
Birds of a Feather Fare Less Well Together: Modeling Predictors of International Student Adaptation
}

\author{
Renee Gibbs ${ }^{1}$, Oya Yerin Güneri ${ }^{2}$, Thomas Pankau ${ }^{3}$ and Lynette Bikos ${ }^{3, *}$ (I) \\ 1 PRIME Research/Department of Veterans Affairs, West Haven, CT 06516, USA; Renee.gibbs@va.gov \\ 2 Department of Educational Sciences/Faculty of Education, Middle East Technical University, 06800 Ankara, \\ Turkey; guneri@metu.edu.tr \\ 3 Department of Clinical Psychology, Seattle Pacific University, Seattle, WA 98119, USA; pankaut@spu.edu \\ * Correspondence: lhbikos@spu.edu; Tel.: +1-206-281-2017
}

Received: 9 February 2020; Accepted: 13 March 2020; Published: 16 March 2020

\begin{abstract}
Sociocultural adaptation to the host country is an important corollary to the psychological well-being of international students. We used structural equation modeling (SEM) to test a model of sociocultural adaptation and psychological wellbeing. International students in Ankara, Turkey $(N=161$, mean age $=22.35)$ completed online surveys. Consistent with our hypotheses, interpersonal connections with host nationals predicted greater sociocultural adaptation $(\beta=0.250, p=0.001)$ and interpersonal connections with co-nationals resulted in poorer psychological adjustment $(\beta=-0.171$, $p=0.025)$. Host-country language proficiency led to better sociocultural adaptation $(\beta=0.262$, $p<0.001$ ), and perceptions of greater cultural distance had a negative impact on both psychological ( $\beta=0.314, p<0.001)$ and sociocultural adaptation $(\beta=0.328, p<0.001)$. Thus, students who were able to engage in relations with host-country nationals fared better. Our results provide insight for sending and receiving institutions regarding the preparation (e.g., exploring cognitive frames for immersion, language skills, reviewing coping strategies) and supportive services (e.g., connection with host country nationals) that will facilitate the adjustment of international students.
\end{abstract}

Keywords: sociocultural adaptation; international students; need for cognitive closure; cultural distance

\section{Introduction}

The proverb "Birds of a feather flock together" reflects the tendency of humans to surround themselves with those similar to themselves, and has been supported in the psychological literature. That is, individuals tend to prefer friends and partners who are similar along sociodemographic [1], genetic [2], and personality [3] variables. However, what effect (relative to other known predictors, such as language proficiency) does this tendency to congregate with others who are similar have on international adaptation? Cross-cultural adjustment and its relation to mental health are critically important areas of study in sojourning populations, including international students.

International students commonly experience psychological difficulties tied to cultural adjustment, including depression, anxiety, and somatic complaints [4]; thus, it is imperative to examine and identify the factors that influence the psychological wellbeing and sociocultural adaptation of individuals in this circumstance. Previous research has identified several critical variables, such as social connectedness [5] and language proficiency [6], that are directly linked to wellbeing. These variables illustrate the importance of interaction with and understanding of one's immediate environment.

The psychology of harmonization is a new psychological perspective focusing on the sustainability of large groups [7], rooted in promoting meaningfulness and wellbeing through intervention at individual and group levels [8]. The psychology of balancing different processes into an organic 
whole at multiple levels (within individuals, between individuals, and between individuals and the natural world) is a pertinent framework for examining international student wellbeing, adaptation, and sustainability.

Drawing on the model of cross-cultural adaption proposed by Searle and Ward $[9,10]$ and related literature, we modeled the effects of intrapersonal, interpersonal, and contextual factors on the psychological and sociocultural adjustment of international students at a prestigious, comprehensive, public university in Ankara, Turkey. This university attracts over 1000 international students to its campus from 85 different countries. The largest proportion come from the Middle East and Central Asia and they enroll in the variety of majors/disciplines that are offered. The overall number of students who are enrolled in undergraduate and graduate programs is 27,000 . While the language of the country and the surrounding community is Turkish, the medium of instruction is English. Turkey is a developing country with a diverse population that has, over the last several decades, seen cultural shifts towards the adoption of several Western ideals, such as individualism and a nuclear family structure, but in many ways retains its collectivistic roots through cultural values of sharing and hospitality. With this specific cultural context established, questions surrounding how international students adjust to this environment can be explored.

\subsection{Sociocultural Adaptation}

Sociocultural adaptation has been defined as "behaviorally based competencies required in various situations and circumstances during cross-cultural transitions" [11] (p. 1476). Examples include adjusting to living, working, and studying in a new environment, and the ability to perceive, understand, and respond appropriately to new cultural situations. Research on international student adjustment has been advanced by Ward and colleagues $[9,12,13]$, who have analyzed numerous variables across their studies, such as homesickness and external loci of control [14], personality and loneliness [10], and cultural distance [12].

Searle and Ward $[9,10]$ provided a theoretical model of adaptation that divides the overall process into two interrelated but distinct domains: (a) psychological adaptation, which encompasses emotional wellbeing as influenced by factors such as personality, coping style, and social support, and (b) sociocultural adaptation, as influenced by variables such as length of stay in the host country, language proficiency, and skill acquisitions related to social norms. The importance of these variables in reducing acculturative stress has been supported in the literature. Social connectedness and language competency [5,6] as well as relationships of international, co-national, and nationals [5] have been shown to be influential in managing acculturative stress. Searle and Ward's theoretical model has been empirically evaluated [12], with periodic revisions in measurement [11]. This framework has been widely used to study intercultural research questions, such as adaptation $[15,16]$ and cultural competence [17], and provides a framework for how to analyze adjustment in our current sample.

\subsection{Multidimensional Predictors of Sociocultural Adaptation}

Because evaluating multiple levels of an individual's environmental context is essential to understanding the multi-level focus of sustainability [18], we modeled the degree of sociocultural adaptation from intrapersonal, interpersonal, and contextual variables. Specifically, our predictor variables included the need for cognitive closure, language fluency, impact of social ties (international, co-national, and host national connections), and cultural distance (the perceived difference between host culture and one's culture of origin).

The need for cognitive closure describes the extent to which an individual feels comfortable with ambiguity in his/her environment [19]; someone who has a high need for cognitive closure may experience more distress in an unfamiliar, foreign environment than someone who is more tolerant of ambiguity. This idea has been supported in a study of the relationship between the need for cognitive closure and the adjustment of European immigrants [20]; as such, we expected to see a similar relationship in our sample of international students. 
Host language proficiency is an important variable in cultural adjustment, as it facilitates contact with and adjustment to a foreign environment; for example, language proficiency can facilitate other variables of interest, such as the number of host-national social connections. Researchers have found language proficiency to be a robust predictor of cultural adjustment [6,21-23]. Relevant to our study is the fact that, while the language of the host culture is Turkish, the official language of the university where the study was conducted is English. All admitted students must pass a rigorous English proficiency exam upon admittance, while Turkish proficiency is not a university requirement. We predicted that Turkish proficiency would increase sociocultural adaptation for international students.

The social context of adjustment is of paramount importance, and previous sustainability research has found social ties, such as academic relational civility, to have profound impacts on wellbeing [24]. In the case of international students, acquaintances with host nationals has facilitated psychological adjustment [5]. Thus, we predicted psychological and sociocultural adjustment would be associated with a greater frequency of social ties with host-country nationals.

Cultural distance analyzes the question of adjustment at a cross-cultural level, taking into consideration perceived discrepancies in home and host cultures. These can present across a variety of domains, such as climate, clothing, language, food, religion, leisure, family structure, and others. Given the distinct features of the Turkish culture, cultural distance is likely to be a key factor in the adjustment of international students at a public university where the study was conducted. Various studies support cultural distance as being strongly associated with sociocultural adaptation. Specifically, Ward and colleagues posited that this occurs via the acquisition of culturally specific skills of the host culture $[9,25]$. The researchers suggested that students who experience a larger distance between home culture and host culture will experience more difficulty in acquiring culturally appropriate skills; in turn, this hinders their sociocultural adaptation. Thus, we predicted that cultural distance would impact both psychological adjustment and sociocultural adaptation.

\subsection{Study Purpose}

To summarize, our study applied Searle and Ward's $[9,10]$ model of adaptation to a sample of international students studying at a public university in Ankara, Turkey. We expected our outcome variables, psychological adjustment and sociocultural adaptation, to be correlated. Furthermore, we anticipated that both outcome variables would be (a) negatively associated with the need for cognitive closure, (b) positively associated with language fluency (in both Turkish and English), and (c) negatively associated with cultural distance. With regard to social ties and our outcome variables, we predicted (a) positive association with frequencies of host-country (Turkish) nationals, (b) a positive association with frequencies of other international students, and (c) a negative association with frequencies of co-nationals.

\section{Materials and Methods}

Institutional Review Board (IRB) approval was obtained from the U.S. and Turkish institutions of higher education prior to collecting the data.

\subsection{Participants}

The participants were 161 international students at a large government-funded university in Ankara, Turkey. The participants' average age was 22.35 years $(S D=3.64)$ with a range of 18 to $40 ; 67 \%$ were male, $27 \%$ were female, and $6 \%$ did not specify. Students who completed the study originated from approximately 40 different countries; the highest percentage of participants were from Iran (16.3\%), Azerbaijan (14.2\%), Turkmenistan (7.1\%), Mongolia (6.4\%), and Indonesia (5.6\%). Of the total number of participants, $37 \%$ were in their first year of study, $15 \%$ were in their second year, $14 \%$ were in their third year, $20 \%$ were fourth year students, and $14 \%$ were graduate students; $4 \%$ did not specify their year in school. 


\subsection{Procedures}

Our data were collected in a natural setting at a single point in time and no variables were manipulated. E-mail invitations were sent to 1249 international students, asking for participation in a study of how the international students adjusted psychologically to study in a foreign country. E-mail letters included a link to the online study posted on surveymonkey.com. The response rate was 203 (16\%). The online survey consisted of 98 items and was estimated to take 20-35 $\mathrm{min}$. The language of instruction at the university where the study was conducted is English; correspondingly, all measures were administered in English.

\subsection{Instruments}

Psychological wellbeing. The Mental Health Inventory (MHI) [26] is a 39 item self-report questionnaire that was designed to measure psychological distress and wellbeing in the general population. Each item on the MHI was rated by participants on a scale from 1 to 6 . Throughout the MHI, the descriptors attached to the 1-6 scale changed, but generally reflected the theme (1) Always to (6) Never. Examples of questions included: "During the past month, how much of the time have you been anxious or worried?" and "During the past month, how often did you feel there were people you were close to?"

The MHI was field-tested in four large samples $(N=5489)$. Veit and Ware [27] indicated strong psychometric support for using five distinct constructs or one summary index and reported a global MHI index at a reliability coefficient of 0.96 . Bikos et al. [28] found support for the MHI in a sample of 32 American expatriate spouses using a 32 item summary index. The authors found reliability coefficients ranging from 0.93 to 0.97 across five administrations. The MHI has also been used cross-culturally with student samples; Al Mutair et al. [29] reported alpha coefficients of 0.58 in its original form and up to 0.85 with the removal of two items in their psychometric assessment within a Saudi Arabian student sample. We used the 10 item subscale assessing psychological wellbeing (PWB); the alpha coefficient for the PWB subscale was 0.90 .

Sociocultural adaptation. The Sociocultural Adaptation Scale (SCAS) $[9,12]$ assesses the degree to which international students adopt culture-specific and adaptive behaviors that assist with cross-cultural transition. The SCAS is a 41 item questionnaire that asks respondents to report the degree of confidence they have in several domains using a five-point scale ranging from 1 (no confidence) to 5 (complete confidence). Sample items include identifying confidence in "understanding the local value system", "using the transportation system", "accepting/understanding the local political system", and "making friends."

Ward and Kennedy conducted a large-scale review of the SCAS psychometric properties in a sample of 16 cross-sectional studies, four longitudinal studies, and one comparative group study [12]. In the 16 cross-sectional studies (with participants from Britain, China, New Zealand, Malaysia, and Hong Kong, to name a few), the authors reported alpha coefficients ranging from 0.75 to 0.91 for the first 10 items of the SCAS, which suggested adequate internal consistency. In addition, the authors demonstrated construct validity with significant correlations of the SCAS to the Zung Self-Rating Depression Scale (range $=0.20-0.62, M=0.38$ ). Other studies have also found high internal consistency alphas for the SCAS, including an alpha of 0.91 [30] and 0.95 [31]. In our study, the alpha coefficient was 0.96 .

Need for cognitive closure. The Need for Cognitive Closure Scale (NCC) [32] assesses tolerance for uncertainty. The original scale (42 items) had five subscales that measured preference for order, intolerance for ambiguity, preference for predictability, close-mindedness, and decisiveness. Kosic et al. [20] omitted the decisiveness scale due to its lack of cross-cultural validity, as measured in samples of Croatian, Italian, and Polish participants; this narrowed the measure to 34 items. Subsequently, Kashima and Loh [5] conducted a principal components analysis and extracted nine items with factor loadings larger than 0.45 . These items included three each from the preference for order, preference for predictability, and discomfort with ambiguity subscales, and yielded an alpha 
coefficient of 0.80 . NCC items are rated on a five-point Likert style scale ranging from 1 (strongly disagree) to 5 (strongly agree). Example items include statements such as "I enjoy having a clear and structured mode of life" and "I dislike unpredictable situations". In our study, the alpha coefficient for the NCC was 0.77 .

Social ties. Participants' social ties were assessed with a reporting method used by Kashima and Loh [5]. Respondents were instructed to list up to 14 friends in the local context on a blank form with two columns. The first column indicated the friend's initials; the second column indicated their country of origin (three choices, including Turkish host-nationals, co-nationals, and internationals). Counts representing the three groups were used as predictor variables. The predictive validity of the instrument was supported in that having personal ties with host country-nationals alleviated psychological adjustment, while ties with other internationals was associated with adjustment in general, and ties with all three types facilitated identification with the university.

Cultural distance. The Cultural Distance Scale (CD) was designed by Bektas [33] according to dimensions identified by the Acculturation Index [13]. The version of the Cultural Distance Scale used in this study was adapted by Ciftci [31] for use in a study of the adaptation process of Turkish immigrants. Participants were asked to indicate the cultural distance from the Turkish culture to their own culture on a five-point scale ( $1=$ totally dissimilar; 5 = totally similar $)$ on 12 separate domains (items), including communication skills, family life, values, friendship, food, language, customs, clothing, social activities, standard of living, world views, and religious beliefs. A lower score on the scale represents greater cultural distance. In prior studies, Cronbach's reliability coefficients have been reported as 0.81 [33] and 0.84 [31]. In our study, the scale performed similarly, with a Cronbach's reliability coefficient of 0.88 .

Demographic questionnaire. An author-constructed demographic questionnaire included age, gender, year of study, selected study major, country of origin/residence, and perceived levels of English and Turkish language proficiency.

\section{Results}

All analyses were completed in $R$ Studio (v. 1.2.5033) with $R$ (v. 3.6.2) in Seattle, Washington, USA, 2019.

\subsection{Missing Data Analysis and Treatment of Missing Data}

Available item analysis (AIA) [34] is a strategy for managing missing data that uses available data for analysis and excludes cases with missing data points only for analyses in which the data points would be directly involved. Parent suggested that AIA is equivalent to more complex methods (e.g., multiple imputation) across a number of variations of sample size, magnitude of associations among items, and degree of missingness. Thus, we utilized Parent's recommendations to guide our approach to managing missing data. Missing data analyses were conducted with the $R$ packages mice (v. 3.7.0), Amelia (v. 1.7.6), and BaylorEdPsych (v. 0.5). We began by deleting cases where missingness was $20 \%$ or more. Of the 161 cases remaining, $70 \%$ of the cases had non-missing data; in fact, missing values represented less than $1 \%$ of the total dataset. For the $30 \%$ of the dataset with missing values, there were 12 patterns of missingness, with the most common $(n=113)$ being non-missing. Of cases with missing values, the number of items ranged between 1 and 14 . Visual inspection of a missing value patterns chart suggested that the missing patterns resembled both monotonicity (e.g., once an individual skipped an item, they discontinued the survey) and haphazard responding. Scales, subscales, and parcels were calculated using Parent's recommendation that some reasonable amount of missingness be allowed. Thus, for parcels containing only three items, we allowed up to $33 \%$ missingness; for all others, we permitted up to $20 \%$ missingness. Applied at this measurement-model level of analysis, Little's MCAR test, which diagnoses whether or not the missing observations are missing completely at random suggested that there was insufficient evidence to reject $\operatorname{MCAR}\left(X^{2}[199]=220.27, p=0.144\right)$. 
Given that our sample sizes were reasonable for the planned analyses and the degree of missingness was low, we specified an FIML (full information maximum likelihood) estimator (which allows missing data in structural equation models) in the structural equation modeling (SEM) analyses. For all others (e.g., alpha coefficients, correlations, hierarchical regression), we used the AIA approach.

\subsection{Creating and Evaluating the SEM Measurement Model}

Bivariate correlations between demographic, predictor, and outcome variables (as well as their means and standard deviations) were calculated with the $R$ psych (v. 1.19.12.131) package and are presented in Table 1.

Table 1. Correlations, means, and standard deviations among measured variables.

\begin{tabular}{|c|c|c|c|c|c|c|c|c|c|c|}
\hline & Variable & 1 & 2 & 3 & 4 & 5 & 6 & 7 & 8 & 9 \\
\hline 1. & NCC & - & & & & & & & & \\
\hline 2. & CDST & 0.118 & - & & & & & & & \\
\hline 3. & CoNat & 0.063 & 0.027 & - & & & & & & \\
\hline 4. & HostNat & -0.012 & 0.097 & $-0.358^{* *}$ & - & & & & & \\
\hline 5. & IntNat & -0.083 & -0.100 & $-0.262^{* *}$ & -0.036 & 一 & & & & \\
\hline 6. & TrkFl & -0.018 & 0.091 & -0.122 & 0.069 & 0.093 & - & & & \\
\hline 7. & EngFl & -0.067 & $-0.225^{* *}$ & -0.117 & 0.019 & 0.126 & 0.087 & 一 & & \\
\hline 8. & PWB & -0.090 & $0.271^{* *}$ & $-0.217^{* *}$ & 0.137 & 0.038 & 0.124 & 0.123 & 一 & \\
\hline 9. & SCAS & -0.188 * & $0.288^{* *}$ & $-0.289 * *$ & $0.343^{* *}$ & 0.029 & $0.325^{* *}$ & 0.138 & $0.431^{* *}$ & - \\
\hline & $M$ & 3.572 & 2.745 & 4.555 & 4.397 & 2.301 & 5.437 & 6.160 & 3.663 & 3.550 \\
\hline & $S D$ & 0.615 & 0.738 & 3.701 & 3.325 & 2.534 & 1.608 & 0.980 & 0.952 & 0.702 \\
\hline
\end{tabular}

Notes: $N=161 .{ }^{* *} p<0.01 ;{ }^{*} p<0.05$. NCC $=$ Need for Cognitive Closure Scale, CDIST $=$ Cultural Distance Scale, CoNat $=$ count of co-national acquaintances, HostNat $=$ count of host-national (Turkish) acquaintances, IntNat $=$ count of international acquaintances, TrkFl = self-rated fluency in Turkish, EngFl = self-rated fluency in English, $\mathrm{PWB}=$ Psychological Wellbeing Scale, SCAS = Sociocultural Adaptation Scale.

SEM analyses were conducted using full information maximum likelihood (FIML) estimation in the lavaan (v. 0.6-5) package; figures were produced with the semPlot (v. 1.1.2) package. Our analytic approach followed the two-step evaluation of first the measurement model, and then the structural model $[35,36]$. In addition to considering the feasibility (direction, magnitude), statistical significance, and appropriateness of the standard errors of the parameter estimates [35], we selected fit criteria for their capacity to assess different aspects of the statistical analysis. Specifically, we followed Kline's [36] recommendation to include the model test statistic (chi-square) and three approximate fit indices (i.e., comparative fit index (CFI), root mean square error of approximation (RMSEA), standardized root mean square residual (SRMR). Structural equation modeling texts $[35,36]$ have documented that researchers disagree on standards for fit criteria and that multiple characteristics, such as sample size and model complexity, should be considered when evaluating the fit of the models. Thus, in our description of each of the fit statistics, we note the general boundaries of the recommendations.

The chi-square goodness of fit test evaluates the discrepancy between the unrestricted sample matrix and the restricted covariance matrix. Although the associated $p$ value indicates adequate fit when the value is non-significant, a large sample size can result in a statistically significant $p$ value [36]. 
The comparative fit index (CFI) is an incremental index, comparing the hypothesized model against the independence or null model. The CFI ranges in value from 0 to 1.00 . The range of acceptable fit begins at 0.90 , with some recommending a lower bound of $0.95[35,36]$. The root mean square error of approximation (RMSEA) takes into account the error of approximation in the population and expresses it per degree of freedom. As such, the fit indicator (customarily reported with a $90 \%$ confidence interval) considers the complexity of the model. In the case of the RMSEA, scores close to 0.00 are more desirable. There appears to be some consensus around values of 0.05 or less being a good fit and values as high as 0.08 representing reasonable errors of approximation in the population, with 0.10 as the upper boundary for acceptability of fit. The SRMR (standardized root mean square residual) represents the average value across all standardized residuals. In a well-fitting model, the SRMR should at least be 0.10 or less, with some arguing that it should be 0.05 or less $[35,36]$.

To compare non-nested models, we reported Akaike's Information Criterion (AIC) and the Bayes Information Criterion (BIC). These criteria simultaneously consider statistical goodness-of-fit, number of estimated parameters, and sample size. The BIC differs in that it imposes greater penalties for model complexity. For both indices, when the values of two or more models are compared, the smaller values represent the better fitting model $[35,36]$. Finally, Hoelter's Critical N $(\mathrm{CN})$ provides an indication of the adequacy of the sample size. Specifically, it estimates a sample size that would be sufficient to yield an adequate model fit for a $\mathrm{X}^{2}$ test; we report the $\mathrm{CN}$ for $p<0.05$ [35]. We provided this value with our measurement model.

Prior to testing a structural model, it is essential that a measurement model be developed that has acceptable fit to the data. For all latent variables, we followed the recommendations of Little, Cunningham, Shahar, and Widaman [37] to create three-item parcels as indicators of each latent variable with multiple indicators (illustrated in Figure 1). Specifically, we followed Little et al.'s instructions for the random assignment approach to parceling. Parcel values were created by requesting the mean of the items represented in each parcel. Because they only had two observed items each, an equality constraint was placed on the factor loadings associated with each of the language fluency latent variables (Turkish, English). This located the construct at the true intersection of the two selected indicators. Because the counts of co-national and host-country social ties were represented by single indicators, we specified the error variance of each to be 0.00 . Once the item parcels were created, we proceeded with the test of our measurement model.

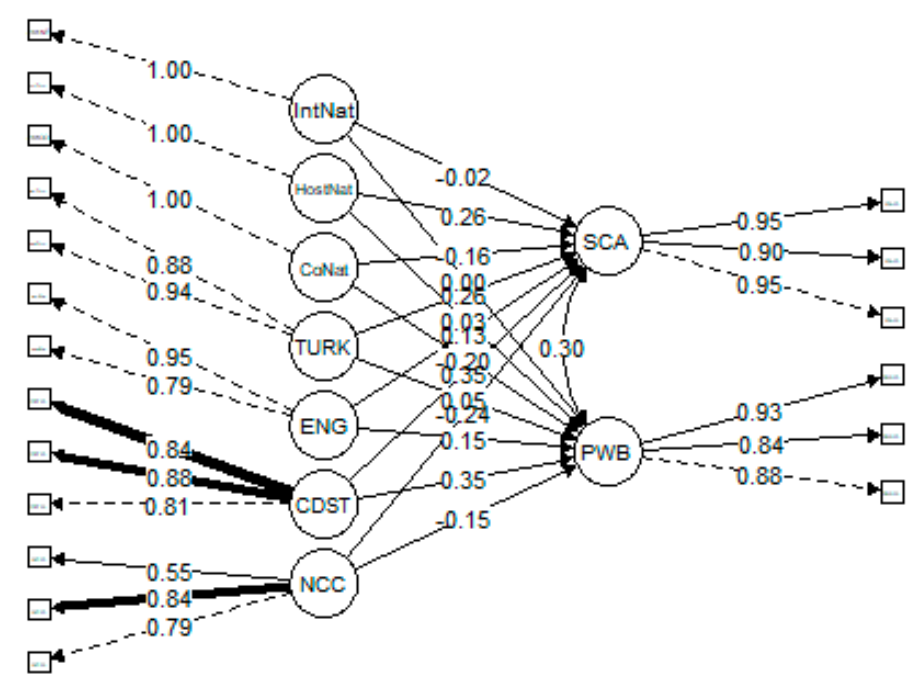

Figure 1. A priori model. This figure illustrates the full structural model with its respective parcels and includes results from the a priori model.

The resultant measurement model had a statistically significant chi-square test $\left(X^{2}[121]\right)=170.852$, $p=0.002)$, but the remaining fit indices met or exceeded the thresholds of acceptability: CFI $=0.971$, 
RMSEA $=0.051(90 \%$ CI $[0.031,0.067]), p=0.463$, SRMR $=0.043$. Additionally, the Hoelter's Critical $N$ for $p<0.050$ indicated a value of 140.16. Because this value is lower than our sample size of 161 , we had empirical support in moving forward with the SEM analyses. Table 2 shows that all loadings of the measured variables on the latent variables were strong and statistically significant.

Table 2. Factor loadings for the measurement model.

\begin{tabular}{|c|c|c|c|c|}
\hline $\begin{array}{c}\text { Construct and } \\
\text { Observed Indicators }\end{array}$ & $\begin{array}{l}\text { Unstandardized } \\
\text { Factor Loading }\end{array}$ & $S E$ & $p$ & $\begin{array}{c}\text { Standardized } \\
\text { Factor Loading }\end{array}$ \\
\hline \multicolumn{5}{|l|}{ Psychological Wellbeing } \\
\hline Parcel 1 & 1.000 & & & 0.875 \\
\hline Parcel 2 & 0.908 & 0.065 & $<0.001$ & 0.84 \\
\hline Parcel 3 & 0.980 & 0.062 & $<0.001$ & 0.926 \\
\hline \multicolumn{5}{|l|}{ Sociocultural Adaptation } \\
\hline Parcel 1 & 1.000 & & & 0.95 \\
\hline Parcel 2 & 0.900 & 0.043 & $<0.001$ & 0.908 \\
\hline Parcel 3 & 1.0014 & 0.041 & $<0.001$ & 0.948 \\
\hline \multicolumn{5}{|l|}{ Need for Cognitive Closure } \\
\hline Parcel 1 & 1.000 & & & 0.754 \\
\hline Parcel 2 & 1.246 & 0.191 & $<0.001$ & 0.879 \\
\hline Parcel 3 & 0.710 & 0.112 & $<0.001$ & 0.539 \\
\hline \multicolumn{5}{|l|}{ Cultural Distance } \\
\hline Parcel 1 & 1.000 & & & 0.811 \\
\hline Parcel 2 & 1.161 & 0.099 & $<0.001$ & 0.881 \\
\hline Parcel 3 & 1.174 & 0.102 & $<0.001$ & 0.835 \\
\hline \multicolumn{5}{|l|}{ Turkish Fluency } \\
\hline Writing Turkish & 1.000 & & & 0.942 \\
\hline Speaking Turkish & 1.000 & & & 0.878 \\
\hline \multicolumn{5}{|l|}{ English Fluency } \\
\hline Writing English & 1.000 & & & 0.791 \\
\hline Speaking English & 1.000 & & & 0.953 \\
\hline \multicolumn{5}{|l|}{ Co-National Ties } \\
\hline Count co-national acquaintances & 1.000 & & & 1.000 \\
\hline \multicolumn{5}{|l|}{ Host National Ties } \\
\hline Count Turkish acquaintances & 1.000 & & & 1.000 \\
\hline \multicolumn{5}{|l|}{ International Ties } \\
\hline Count international acquaintances & 1.000 & & & 1.000 \\
\hline
\end{tabular}

\subsection{Evaluating the Structural Model}

We approached model development with a model-generating approach [35,38]. That is, we expected to reject our a priori model (Figure 1) and planned to modify and re-estimate it, obtaining a parsimonious model that not only fit the data well, but that was also meaningful and interpretable. In this sense, the theoretical model supported by literature informed the specification of the relations between predictor and outcome variables, yet we acknowledged up front that our predictions would likely be inadequate. Our first step was to specify our a priori model. Second, we respecified the a priori model by trimming non-significant paths. Third, we evaluated modification indices [35] to determine if adding covariances between the errors or predictor variables would improve the model fit. In both the second and third phases, we trimmed or added each path one at a time, re-evaluating between re-specifications.

The a priori model is illustrated in Figure 1. This model included seven predictor variables, including the NCC, CD, social ties (counts of co-national, host-national, and international friends), and language fluency scales (English, Turkish). The endogenous variables were PWB and SCAS. Because the previous literature suggests that these two are strongly related, we allowed these to co-vary. While the overall fit of our a priori model was acceptable (see Table 3 for a summary of fit statistics and results 
of the chi-square difference test), we continued with the plan for re-specification. Table 4 presents a summary of the regression and covariance paths.

Table 3. Summary of fit indices in nested structural models.

\begin{tabular}{|c|c|c|c|c|c|c|c|c|c|c|}
\hline Model & $X^{2}$ & df & $p$ & $\begin{array}{c}\text { Model } \\
\text { Comparison }\end{array}$ & $\Delta X^{2}$ & $\Delta \mathrm{df}$ & AIC/BIC & CFI & RMSEA & SRMR \\
\hline A priori & 227.25 & 142 & $<0.001$ & - & - & - & $7560.7 / 7767.2$ & 0.950 & $\begin{array}{c}0.061 \\
\left(C I_{90} 0.046\right. \\
0.076)\end{array}$ & 0.078 \\
\hline Trimmed & 123.26 & 99 & 0.054 & $\begin{array}{l}\text { A priori to } \\
\text { Trimmed }\end{array}$ & 103.00 * & 43 & $6070.2 / 6233.5$ & 0.985 & $\begin{array}{c}0.039 \\
\left(C I_{90} 0.000\right. \\
0.059)\end{array}$ & 0.078 \\
\hline Final & 103.25 & 98 & 0.390 & $\begin{array}{l}\text { Trimmed to } \\
\text { Final }\end{array}$ & $20.00 *$ & 1 & $6052.0 / 6218.6$ & 0.998 & $\begin{array}{c}0.014 \\
\left(C I_{90} 0.000\right. \\
0.045)\end{array}$ & 0.066 \\
\hline
\end{tabular}

Note: ${ }^{*} p<0.05$.

Table 4. Summary of effects in the structural model.

\begin{tabular}{|c|c|c|c|c|c|c|c|c|c|}
\hline \multicolumn{6}{|c|}{ A Priori Model } & \multicolumn{4}{|c|}{ Final Model } \\
\hline IV & DV & $B$ & $S E$ & $p$ & $\beta$ & $B$ & $S E$ & $p$ & $\beta$ \\
\hline NCC & PWB & -0.253 & 0.140 & 0.070 & -0.153 & - & - & - & - \\
\hline $\mathrm{CD}$ & PWB & 0.530 & 0.132 & $<0.001$ & 0.348 & 0.479 & 0.131 & $<0.001$ & 0.314 \\
\hline CoNat & PWB & -0.051 & 0.022 & 0.023 & -0.198 & -0.060 & 0.020 & 0.003 & -0.234 \\
\hline HostNat & PWB & 0.007 & 0.024 & 0.756 & 0.026 & - & - & - & - \\
\hline IntNat & PWB & 0.002 & 0.031 & 0.957 & 0.004 & - & - & - & - \\
\hline TrkFl & PWB & 0.032 & 0.050 & 0.526 & 0.051 & - & - & - & - \\
\hline EngFl & PWB & 0.160 & 0.087 & 0.067 & 0.152 & - & - & - & - \\
\hline NCC & SCAS & -0.287 & 0.096 & 0.003 & -0.239 & -0.245 & 0.094 & 0.009 & -0.202 \\
\hline $\mathrm{CD}$ & SCAS & 0.388 & 0.086 & $<0.001$ & 0.351 & 0.364 & 0.085 & $<0.001$ & 0.328 \\
\hline CoNat & SCAS & -0.030 & 0.015 & 0.044 & -0.160 & -0.032 & 0.014 & 0.025 & -0.171 \\
\hline HostNat & SCAS & 0.054 & 0.016 & 0.001 & 0.259 & 0.052 & 0.015 & 0.001 & 0.250 \\
\hline IntNat & SCAS & -0.005 & 0.020 & 0.818 & -0.017 & - & - & - & - \\
\hline TrkFl & SCAS & 0.118 & 0.033 & $<0.001$ & 0.264 & 0.117 & 0.031 & $<0.001$ & 0.262 \\
\hline EngFl & SCAS & 0.100 & 0.057 & 0.082 & 0.130 & - & - & - & - \\
\hline \multicolumn{10}{|c|}{ Covariances } \\
\hline \multicolumn{2}{|c|}{ PWB \& SCAS } & 0.140 & 0.044 & $<0.001$ & 0.328 & 0.163 & 0.046 & $<0.001$ & 0.337 \\
\hline \multicolumn{2}{|c|}{ CoNat \& HostNat } & & & & & -4.362 & 1.070 & $<0.001$ & -0.357 \\
\hline
\end{tabular}

Notes: NCC $=$ Need for Cognitive Closure, $\mathrm{CD}=$ Cultural Distance Scale, $\mathrm{CoNat}=$ count of co-national social ties, HostNat = count of host-country social ties; IntNat = count of international social ties; TrkFl = Turkish Fluency, EngFl = English Fluency, PWB = Psychological Wellbeing, SCAS = Sociocultural Adaptation Scale.

Our next model was created by trimming seven non-significant paths from the a priori model. As shown in Table 3, the decrease in the chi-square and the increase in the CFI indicated significant improvements to the model. As planned, we next evaluated the modification indices to assess whether freeing predictor variables to covary would improve model fit in a meaningful way. Our review suggested that allowing the counts of host-national and co-national ties to covary would reduce the chi-square value by 18.72 points. As shown in Table 3, the re-specification was a statistically significant improvement. Our final model accounted for $34 \%$ of the variance in the endogenous variable sociocultural adjustment (SCAS), and $15 \%$ of the variance in the endogenous variable psychological adjustment (PWB). Table 4 provides a summary of the effects in the a priori and final models. The final model is shown in Figure 2. 


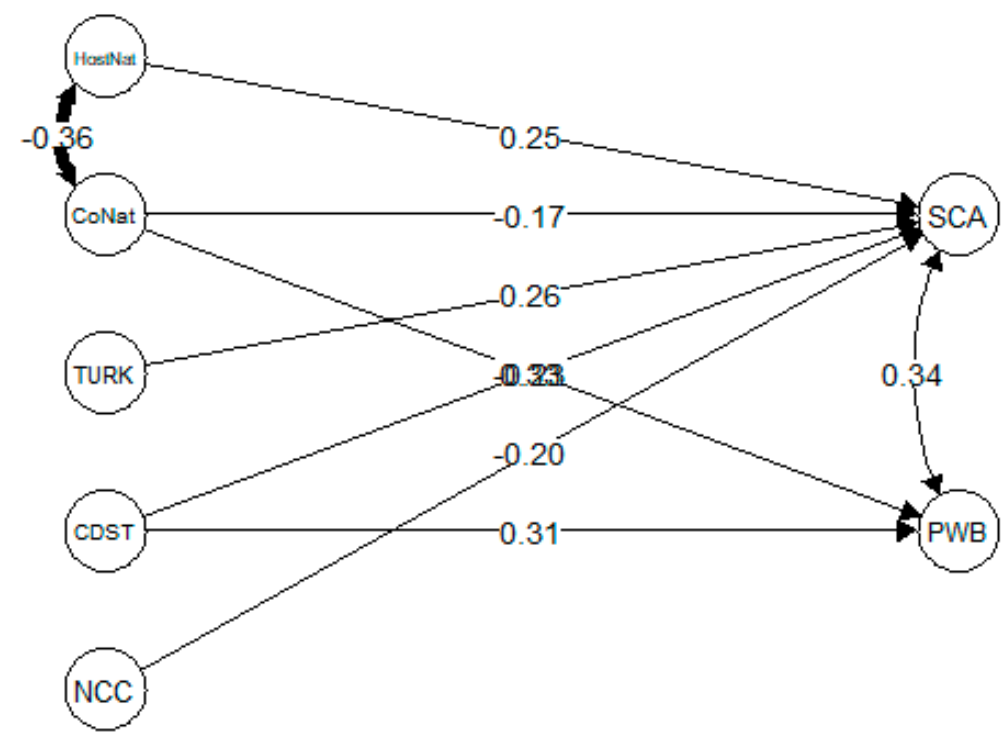

Figure 2. Final model. This figure represents the structural model after non-significant paths were trimmed and covariances were added.

\section{Discussion}

In our investigation of the intrapersonal, interpersonal, and contextual factors that contribute to international student adjustment, we utilized a model-generating approach to trim non-significant paths and add promising paths to a structural equation model to predict psychological and sociocultural adaptation among international students studying at a public university in Ankara, Turkey. Predictors included the need for cognitive closure, language fluency, social ties, and cultural distance. Our final model fit the data well, was more parsimonious than the originally specified model, and was theoretically sound.

The development of this model began with Searle and Ward's conceptualization of acculturation [10] - that sociocultural and psychological adjustment are distinct but correlated factors. The final model accounted for $15 \%$ of psychological adjustment and $34 \%$ of sociocultural adaptation; these two scales had a significant correlation of 0.34 . This is consistent with Searle and Ward's studies and lends support to their theoretical model of acculturation.

As predicted, the need for cognitive closure was significantly negatively related with sociocultural adjustment. That is, students with a greater need for certainty from their environment had a more difficult time adopting culturally-specific behaviors in the new environment. Somewhat unexpectedly and counter to prior literature $[5,20]$, the need for cognitive closure had a non-significant effect on psychological wellbeing and was trimmed from the model.

Language proficiency in both Turkish and English was associated with stronger sociocultural adjustment; English proficiency also predicted stronger psychological wellbeing. Given that Turkish would assist an international student in the larger community, but English is required for academic success, this finding is sensible. The important association between language and sociocultural adaptation is consistent with Deygers' [39] findings. Specifically, Deygers used a mixed-method approach to learn from quantitative findings that international students made little-to-no gains in the language of the host country in the first eight months of their adjustment. The results of the qualitative component of the study suggested that language learning is predicated upon opportunities to have meaningful social interactions with host-country nationals. Together with our results, an important follow-up study could be the mediating effect of social interaction upon the relationship between language acquisition and sociocultural adaptation and psychological wellbeing.

The count of co-national friends had inverse relationships with both psychological adjustment and sociocultural adaptation. Conversely, having a larger number of host-national (Turkish) friends 
predicted greater sociocultural adjustment, but was not associated with psychological wellbeing. The variable that assessed frequency of international friends was trimmed from the model. This finding speaks to the importance of international students connecting with host nationals and the risk associated with socializing primarily with co-nationals. While the negative effect of co-national ties was not explicitly predicted by the literature, it is consistent with Berry's [40] notion of separation as an acculturation strategy. When individuals employ this approach, they avoid contact with members of the host location and affiliate with members of their own cultural identity. Not surprisingly, this strategy does not aid adjustment. We were surprised that international friends had non-significant effects on sociocultural adaptation and psychological wellbeing. We had hoped that international friends would encourage each other to adventure together and to learn about each other and the host country.

In a manner consistent with the literature $[9,10,25]$, cultural distance was a significant predictor; students who came from countries they perceived to be culturally similar to Turkey had higher psychological and sociocultural adjustment.

The findings of our study align with recent perspectives of psychological harmonization (i.e., balancing different processes into an organic whole at multiple levels-within individuals, between individuals, and between individuals and the natural world) [41]. Such an approach emphasizes strength-building and preventative action that, together, facilitate harmonization. Particularly within the context of cross-cultural environments, our findings suggest that language proficiency and relationships with host nationals facilitate greater harmony in the process of adaptation. Our sample consists of individuals experiencing cultural friction, ranging from differences in everyday behavioral norms to differences in collectivist-individualist mentalities. Thus, the psychology of harmonization and its emphasis on how individuals balance their relationship with their immediate environment provides a useful lens to view the processes related to cultural adjustment. The practical application of our findings can lead to enhanced harmonization in a cross-cultural setting, which subsequently leads to greater sustainability. The psychology of sustainability is concerned with how to facilitate the sustainability of human relationships, communities, and the wellbeing of groups. This study adds to our understanding of sustainability in a cross-cultural context by highlighting the importance of variables, such as host-national social ties during sociocultural adaptation, emphasizing the need for connectedness, community, and relationships in establishing the sustainability of international student populations.

\subsection{Limitations}

The results and implications of this study should be tempered by its limitations, the most significant of which is the sample size. Of the 203 students who began the online surveys, only 161 had sufficient non-missing data that were included in the final analyses. This may have been due to a lack of completion incentive. The process of data collection itself was complicated by a lengthy institutional review process at two separate universities, which restricted our ability to collect pencil-and-paper surveys. Low student attendance and data collection spanning only two semesters (three would have been ideal) were also factors that added to the difficult data collection phase.

Our ability to make causal inferences is limited by our study's cross-sectional nature. Furthermore, this study may have been better served with a different selection of variables. For example, we asked for the academic years of the students (e.g., first year, second year, etc.) instead of a time-in-country measure, such as months in the country or date of arrival. Thus, relations such as co-national versus host-national friends might differ as a function of time. For example, students who had been in-country longer might also have more host-national friends.

Finally, our model-generating approach (i.e., trimming non-significant paths and adding significant ones) may have captured sample-specific characteristics [36,37] that may not replicate. Despite the diversity of our sample, the results speak to the adjustment process of our international students at a specific place and time, which may look very different at another university or in another city in Turkey. 


\subsection{Future Research and Practical Applications}

The results of this study add to the literature on international adjustment, specifically for students in this part of the world, and provide support for Ward and Searle's models of cultural adjustment $[9,10]$. Future researchers could evaluate this model in different populations or different regions. Alternatively, researchers may investigate the covarying growth trajectories of these variables in a longitudinal design (e.g., having students complete surveys at 3, 6, and 12 month timepoints).

Our results have practical implications for student preparedness for cultural transitions and may inform university interventions. First, our results tell us a bit about the sojourning student in this specific context. The average (rounding to the nearest whole number) student had three co-national, five host-national, and two international acquaintances. Students considered themselves to be moderately fluent in the host-country language (Turkish) and even more so in English. The average student had mid-range levels of need for cognitive closure and psychological wellbeing. They perceived some dissimilarity between home and host cultures and were moderately confident in their sociocultural adaptation. That said, variation around all of these variables was substantial. The strength of the associations found in our study paired with the variability suggests that sociocultural adaptation and psychological wellbeing could be enhanced through individual and institutional intervention, such as preparedness for education abroad.

In a recent investigation of student readiness for study abroad, researchers [42] reported that social cognitive career theory [43] served as a useful theoretical framework for both conceptualizing predictors of sociocultural adaptation and intervening. Specifically, study abroad students perceived that past personal performance accomplishments (e.g., international and domestic travel) would be the strongest contributors to successful adaptation to the host-country environment. This was followed by intentional pre-departure preparation and practice (e.g., language lessons, orientation) and vicarious learning experiences from family, friends, and acquaintances who had similar experiences. Considering students' variability in readiness, Bikos et al. [42] recommended that (to the degree possible) international experiences be incrementally graded. Our results suggest that language proficiency and perceived cultural distance between home and host countries would be important considerations in selecting a global experience.

Beyond student selection, the need for psycho-educational interventions at pre-departure and re-entry or repatriation is also indicated. Prior to departure, such interventions may include individual advising/counseling, classes, workshops/seminars, and support groups that help students develop realistic expectations and coping skills. Pre-departure information should review cultural differences and similarities in education systems and in the host culture. Returnees (peers) may be a useful resource for future sojourners, in that they offer a unique credibility and accessibility for delivering critical information to the pre-departed students [44]. With regard to cultivating coping skills, Manning, Frieders, and Bikos [45] have recommended that students reflect on the strategies that have served them in other contexts and imagine how they might be adapted for the international context. In this way, sociocultural adaptation is not pathologized, but rather viewed as another (albeit novel) developmental challenge.

Cultural differences are a critical topic for pre-departure consideration. Awareness of cultural distance may be fostered by encouraging students to think of their own cultures and their perceptions of other cultures. Seminars and exercises that prompt reflective thinking on one's own culture can help prepare students for more openness, flexibility, and curiosity when engaging with other cultures [46]. Language proficiency, including familiarity with regional accents/dialects, has consistently been shown to be a powerful predictor of sociocultural adjustment and should be emphasized [4].

Host universities can predict that the initial month of transition may be the most difficult for many students and, therefore, plan to offer immediate services and social/cultural opportunities [44]. Depending on the context, resources might include personal tutors, chaplaincy [47], counseling that emphasizes coping skills [48], opportunities to facilitate connections with professors and international students [49], and university-sponsored social functions that foster connections with host-national 
students. Information about student welfare services (e.g., student counseling) should ideally be made available in the initial week; staff/faculty such as counselors who will be engaging with students are recommended to have training in serving clients of diverse backgrounds [47].

As we close the article, we might suggest that "birds of different feathers adapt better together." Such adaptation is further facilitated by the sojourning students' open-mindedness, ability to communicate in the language of the host country and university, and perception of the degree of difference between home and host countries.

Author Contributions: Conceptualization, R.G., O.Y.G., and L.B.; methodology, R.G. and L.B.; software, R.G. and L.B.; formal analysis, R.G. and L.B.; investigation, R.G. and O.Y.G.; resources, R.G. and O.Y.G.; data curation, R.G. and L.B.; writing—original draft preparation, R.G., T.P., and L.B.; writing—review and editing, R.G., T.P., L.B., and O.Y.G.; visualization, T.P. and L.B.; supervision, L.B. and O.Y.G.; project administration, R.G. and O.Y.G. All authors have read and agreed to the published version of the manuscript.

Funding: This research received no external funding.

Acknowledgments: We are grateful for the Department of Educational Sciences for hosting the first author for the collection of this data.

Conflicts of Interest: The authors declare no conflict of interest.

\section{References}

1. Rushton, J.P. Genetic similarity, human altruism, and group selection. Behav. Brain Sci. 1989, 12, 503-559. [CrossRef]

2. Rushton, J.P.; Bons, T.A. Mate choice and friendship in twins: Evidence for genetic similarity. Psychol. Sci. 2005, 16, 555-559. [CrossRef] [PubMed]

3. Youyou, W.; Stillwell, D.; Schwartz, H.A.; Kosinski, M. Birds of a feather do flock together: Behavior-based personality-assessment method reveals personality similarity among couples and friends. Psychol. Sci. 2017, 28, 276-284. [CrossRef] [PubMed]

4. Mesidor, J.K.; Sly, K.F. Factors that contribute to the adjustment of international students. J. Int. Stud. 2016, 6, $262-282$.

5. Kashima, E.S.; Loh, E. International students' acculturation: Effects of international, co-national, and local ties and need for closure. Int. J. Intercult. Relat. 2006, 30, 471-485. [CrossRef]

6. Yeh, C.J.; Inose, M. International students' reported English fluency, social support satisfaction, and social connectedness as predictors of acculturative stress. Couns. Psychol. Q. 2003, 16, 15-28. [CrossRef]

7. Di Fabio, A. Positive Healthy Organizations: Promoting well-being, meaningfulness, and sustainability in organizations. Front. Psychol. Organ. Psychol. 2017, 8, 1938-1954. [CrossRef]

8. Di Fabio, A. The psychology of sustainability and sustainable development for well-being in organizations. Front. Psychol. Organ. Psychol. 2017, 8, 1534-1540. [CrossRef]

9. Searle, W.; Ward, C. The prediction of psychological and socio-cultural adjustment during cross-cultural transitions. Int. J. Intercult. Relat. 1990, 14, 449-464. [CrossRef]

10. Ward, C.; Searle, W. The impact of value discrepancies and cultural identity on psychological and socio-cultural adjustment of sojourners. Int. J. Intercult. Relat. 1991, 15, 209-225. [CrossRef]

11. Wilson, J.; Ward, C.; Fetvadjiev, V.H.; Bethel, A. Measuring cultural competencies: The development and validation of a revised measure of sociocultural adaptation. J. Cross Cult. Psychol. 2017, 48, 1475-1506. [CrossRef]

12. Ward, C.; Kennedy, A. The measurement of socio-cultural adaptation. Int. J. Intercult. Relat. 1999, 23, 659-677. [CrossRef]

13. Ward, C.; Rana-Deuba, A. Acculturation and adaptation revisited. J. Cross Cult. Psychol. 1999, 30, 372-392. [CrossRef]

14. Ward, C.; Kennedy, A. Psychological and socio-cultural adjustment during cross-cultural transitions: A comparison of secondary students overseas and at home. Int. J. Psychol. 1993, 28, 129-147. [CrossRef]

15. Hippler, T.; Caligiuri, P.M.; Johnson, J.E.; Baytalskaya, N. The development and validation of a theory-based expatriate adjustment scale. Int. J. Hum. Resour. Manag. 2014, 25, 1938-1959. [CrossRef] 
16. Wu, E.K.; Mak, W.W. Acculturation process and distress: Mediating roles of sociocultural adaptation and acculturative stress. Couns. Psychol. 2012, 40, 66-92. [CrossRef]

17. Wilson, J.; Ward, C.; Fischer, R. Beyond culture learning theory: What can personality tell us about cultural competence? J. Cross Cult. Psychol. 2013, 44, 900-927. [CrossRef]

18. Di Fabio, A.; Rosen, M.A. Opening the black box of psychological processes in the science of sustainable development: A new frontier. Eur. J. Sustain. Dev. Res. 2018, 2, 47-51. [CrossRef]

19. Kruglanski, A.W.; Webster, P.M. Motivated closing of the mind: "Seizing" and "freezing". Psychol. Rev. 1996, 103, 263-283. [CrossRef]

20. Kosic, A.; Kruglanski, A.W.; Pierro, A.; Mannetti, L. The social cognition of immigrants' acculturation: Effects of the need for closure and the reference group at entry. J. Personal. Soc. Psychol. 2004, 86, 796-813. [CrossRef]

21. Duru, E.; Poyrazli, S. Personality dimensions, psychosocial-demographic variables, and English language competency in predicting level of acculturative stress among Turkish international students. Int. J. Stress Manag. 2007, 14, 99-110. [CrossRef]

22. Mallinckrodt, B.; Leong, F.T.L. International graduate students, stress, and social support. J. Coll. Stud. Dev. 1992, 33, 71-78.

23. Poyrazli, S.; Kavanaugh, P.R.; Baker, A.; Al-Timimi, N. Social support and demographic correlates of acculturative stress in international students. J. Coll. Couns. 2004, 7, 73-82. [CrossRef]

24. Di Fabio, A.; Kenny, M. Academic relational civility as a key resource for sustaining well-being. Sustainability 2018, 10, 1914-1926. [CrossRef]

25. Ward, C.; Kennedy, A. Locus of control, mood disturbance, and social difficulty during cross-cultural transitions. Int. J. Intercult. Relat. 1992, 16, 175-194. [CrossRef]

26. Stewart, A.L.; Ware, J.E., Jr. Measuring Functioning and Well-Being: The Medical Outcomes Study Approach; Duke University Press: Durhum, NC, USA, 1996.

27. Veit, C.T.; Ware, J.E. The structure of psychological distress and well-being in general populations. J. Consult. Clin. Psychol. 1983, 51, 730-742. [CrossRef]

28. Bikos, L.H.; Uruk, A.C.; Guneri, O.Y.; Engen-Demir, C.; Sumer, Z.H.; Danielson, S.; DeVries, S.; Bilgen, W.A. A repeated measures investigation of the first-year adaptation experience of the female expatriate spouse living in Turkey. J. Career Dev. 2007, 34, 5-24. [CrossRef]

29. Al Mutair, A.; Al Mohaini, M.; Fernandez, R.; Moxham, L.; Lapkin, S.; Ham-Baloyi, W.T. Psychometric testing of the mental health inventory in an Arabian context: Cross-cultural validation study. Nurs. Open 2018, 5 , 376-383. [CrossRef]

30. Klemens, M.J.; Bikos, L.H. Psychological well-being and socio-cultural adaptation in college-aged, repatriated, missionary kids. Ment. Health Relig. Cult. 2009, 12, 721-734. [CrossRef]

31. Ciftci, A. The Adaptation Process of Turkish Individuals Living in the United States: An Integrated Framework. Ph.D. Thesis, University of Memphis, Memphis, TN, USA, 2006.

32. Webster, D.M.; Kruglanski, A.W. Individual differences in need for cognitive closure. J. Personal. Soc. Psychol. 1994, 67, 1049-1062. [CrossRef]

33. Bektas, D.Y. Psychological Adaptation and Acculturation of the Turkish Students in the U.S.A. Ph.D. Thesis, Middle East Technical University, Ankara, Turkey, 2004.

34. Parent, M.C. Handling item-level missing data: Simpler is just as good. Couns. Psychol. 2013, 41, 568-600. [CrossRef]

35. Byrne, B.M. Structural Equation Modeling with AMOS: Basic Concepts, Applications, and Programming, 3rd ed.; Routledge: New York, NY, USA, 2016.

36. Kline, R.B. Principles and Practice of Structural Equation Modeling, 4th ed.; Guilford Press: New York, NY, USA, 2016.

37. Little, T.D.; Cunningham, W.A.; Shahar, G.; Widaman, K.F. To parcel or not to parcel: Exploring the question, weighing the merits. Struct. Equ. Model. 2002, 9, 151-173. [CrossRef]

38. Joreskog, K.G. Testing structural equation models. In Testing Structural Equation Models; Bollen, K.A., Long, J.S., Eds.; Sage: Newbury Park, CA, USA, 1993; pp. 294-316.

39. Deygers, B. How institutional and interpersonal variables impact international L2 students' language gains at university. System 2018, 76, 91-102. [CrossRef]

40. Berry, J.W. Lead article: Immigration, acculturation, and adaptation. Appl. Psychol. Int. Rev. 1997, 46, 5-34. [CrossRef] 
41. Di Fabio, A.; Tsuda, A. The psychology of harmony and harmonization: Advancing the perspectives for the psychology of sustainability and sustainable development. Sustainability 2018, 10, 4726-4740. [CrossRef]

42. Bikos, L.H.; Manning, S.B.; Frieders, Z.J. Ready or not here I come: A qualitative investigation of students' readiness perceptions for study abroad/away. Int. Perspect. Psychol. Res. Pract. Consult. 2019, 8, 78-91. [CrossRef]

43. Lent, R.W. Social cognitive career theory. In Career Development and Counseling: Putting Theory and Research to Work, 2nd ed.; Brown, S.D., Lent, R.W., Eds.; Wiley: Hoboken, NJ, USA, 2013; pp. 115-146.

44. Quan, R.; He, X.; Sloan, D. Examining Chinese postgraduate students' academic adjustment in the UK higher education sector: A process-based stage model. Teach. High. Educ. 2016, 21, 326-343. [CrossRef]

45. Manning, S.; Frieders, Z.; Bikos, L.H. When does global learning begin: Recognizing the value of student experiences prior to study away. In Mind the Gap: Global Learning at Home and Abroad; Namaste, N., Sturgill, A., Sobania, N., Berg, M.V., Eds.; Stylus: Sterling, VA, USA, 2020.

46. Campbell, C.J.; Walta, C. Maximising intercultural learning in short term international placements: Findings associated with orientation programs, guided reflection and immersion. Aust. J. Teach. Educ. 2015, 40, 1-15. [CrossRef]

47. Brown, L.; Aktas, G. Fear of the unknown: A pre-departure qualitative study of Turkish international students. Br. J. Guid. Couns. 2011, 39, 339-355. [CrossRef]

48. Harrison, J.K.; Brower, H.H. The impact of cultural intelligence and psychological hardiness on homesickness among study abroad students. Front. Interdiscip. J. Study Abroad 2011, 21, 41-62.

49. Shapiro, S.; Farrelly, R.; Zuzana, T. Fostering International Student Success in Higher Education; TESOL International Association: Alexandria, VA, USA, 2014.

(C) 2020 by the authors. Licensee MDPI, Basel, Switzerland. This article is an open access article distributed under the terms and conditions of the Creative Commons Attribution (CC BY) license (http://creativecommons.org/licenses/by/4.0/). 